\title{
BEHAVIOURAL INDUCTION OF OVULATION IN THE OESTROUS RABBIT
}

\author{
R. E. STAPLES \\ The Worcester Foundation for Experimental Biology, Shrewsbury, \\ Massachusetts, U.S.A.
}

(Received 12th April 1966)

\begin{abstract}
Summary. The incidence of ovulation was determined among oestrous 'Dutch-belted' does following exposure to varying degrees of behavioural stimulation short of coitus. The mounting of does by a male did not induce ovulation even though on more than 240 occasions the females assumed the fully arched position during which vaginal penetration was prevented by deflection of the males' hind quarters. Receptive females did not ovulate after thirty-five exposures as teasers for semen collection by artificial vagina, or if retained in close proximity to the male in addition to being mounted once daily over a 2 -week period. Ovulation did occur among submissive oestrous does if they were repeatedly mounted by oestrous or anoestrous does while caged in pairs for periods ranging from 1 to 17 days, but ovulation was not observed among females that assumed only the dominant role.
\end{abstract}

\section{INTRODUCTION}

Ovulation in the rabbit is normally induced by the act of coitus (Heape, 1905), but the persistence of reports of so-called 'spontaneous' ovulations occurring among non-mated does (Walton \& Hammond, 1928; Hill, Parkes \& White, 1934; Pincus, 1948; Nalbandov, 1958) has made investigators aware of the possibility of additional ovulation-inducing factors. A small percentage of does are known to ovulate following mechanical stimulation of the vagina and/or the cervix (e.g. Yamane \& Egashira, 1925; Hammond \& Asdell, 1926; Shibata, 1931; Carlyle \& Williams, 1961). This percentage can be increased by oestrogen and/or progesterone administration during winter and spring months (Sawyer, 1949; Sawyer, Everett \& Markee, 1950; Sawyer, 1959). Templeton (1940) found that force mating of non-receptive females caused only two of five to ovulate, and only five of twenty does maintained a pregnancy to term if force bred to an intact male 17 or more days after a sterile mating. A low incidence of ovulation after force mating was also reported by Foote, Hafs, Staples, Gregoire \& Bratton (1963). Mere rubbing of the vulva was reported to cause ovulation in two of four attempts (Hammond, 1925); however, this finding was not confirmed by Shibata (1931). The mounting of an oestrous female by a male was also reported to cause ovulation in two of six 
does (Hammond, 1925) and in one of three does (Templeton, 1940), even though entry of the vagina was not permitted and the vulvas were not rubbed. Hammond \& Marshall (1914) and Brooks (1937) each reported single cases of ovulation following the mounting of one female by another. Others have referred to this phenomenon (e.g. Walton \& Hammond, 1928; Hammond, 1930; Fee \& Parkes, 1930; Templeton, 1940; Asdell, 1946) but without presentation of additional data. It has also been stated that the mere proximity of an oestrous doe to a buck may cause ovulation (Brooks, 1937; Garcia \& Rock, 1958), but data were not presented.

This investigation was conducted to determine the relative importance of certain behavioural conditions for inducing ovulation in the oestrous doe.

\section{METHODS AND RESULTS}

Mature, Dutch-belted rabbits weighing more than $1.75 \mathrm{~kg}$ were used between the months of January and June from 1963 to 1966 . They were housed individually, unless otherwise specified, in quarters that were lighted from 06.00 hours to 18.00 hours. Purina Rabbit Pellets and water were provided ad libitum.

For testing receptivity to the male, the female was always placed in the buck's cage. Upon being mounted arching of the doe's hindquarters (lordosis) indicated oestrus or receptivity to the male. Coitus was prevented among receptive does by pushing aside the hindquarters of the buck. The occurrence of ovulation was determined by laparotomy and examination of the ovaries for the presence of corpora lutea or ovulation points. Autopsies were performed following killing by cervical dislocation.

\section{Experiment $1(a)$ : Single mount without ejaculation}

Virgin does were retained in individual cages for a pre-experimental period of at least 18 days. Receptivity of each female was then determined, following which all does were returned to their cages. Laparotomy 10 days later failed to reveal corpora lutea on the ovaries of any of the fourteen receptive does tested. Large follicles, however, were present in each case.

\section{Experiment $1(b)$ : Single daily mount with ejaculation}

The procedure of Experiment 1(a) was used except that males mounting receptive does were allowed to ejaculate into an artificial vagina to determine whether mounting plus the clasp of the male at the time of ejaculation would stimulate ovulation in the doe. No corpora lutea or ovulation points were noted at laparotomy $24 \mathrm{hr}$ after the first mounting. Six days later, the receptive females were mounted in the manner described once daily for 6 days. No corpora lutea were observed at laparotomy on the 7 th day among any of the five does tested.

Experiment 2: Single, daily mounts plus continued close association with the buck

Several virgin does were laparotomized to verify that corpora lutea were not present on their ovaries. Beginning on the succeeding day, receptive does 
were housed in individual cages wired to a central cage occupied by a male in such a way that each male had four oestrous does around him. The cages used were $24 \mathrm{in}$. high, $18 \mathrm{in}$. wide and $20 \mathrm{in}$. long with $1-\times 2$-in. mesh and were constructed from 13 gauge wire. These cage units were placed upon a layer of hay and neither the litter nor the cages were cleaned for the duration of the experiment. Hence, the receptive does could view the male and supposedly detect his scent for this period. In addition, each doe in a cage unit was placed into the male's cage once daily to record receptivity. Coitus was not permitted. After 14 days of such exposure each doe was returned to an individual cage for 1 day and then autopsied.

The twelve cages wired to three cages containing males were filled with receptive females within 6 days after laparotomy. The total number of arches recorded were 152 of a total of 168 mounting exposures. Thirteen arching failures were due to one doe that arched once and then did not arch thereafter. No corpora lutea were observed on the ovaries of the twelve females tested. Since corpora lutea were not present on the ovaries of the non-receptive animal, it is supposed that she was becoming anoestrous at the initiation of the experiment.

Normal pregnancy and parturition ensued when coitus was permitted on the day following laparotomy in a further two does, illustrating that the oestrous does would still mate and retain a pregnancy shortly after laparotomy.

\section{Experiment 3: Pairing of oestrous does}

Mature, virgin does were tested for receptivity, as described previously, after an 18-day isolation period, and the receptive females were laparotomized the following day. No ovulation points or corpora lutea were present on their ovaries. The females were then housed in pairs for 2 weeks in cages strange to both members of each pair. When established, the dominant doe (doe assuming the sexual role of the male) and the submissive member of each pair were noted. Receptivity was tested daily during the 2-week experimental period. If a doe failed to arch for the particular buck used, she was tested further; if no arches occurred after being placed with three bucks, the doe was termed 'non-receptive' and was autopsied on the succeeding day, after being caged singly during the intervening period. Receptive does replaced those which became non-receptive as the study progressed. At the termination of the 2-week period all remaining does were autopsied after spending 1 day in individual cages. The ovaries of all autopsied does were examined for the presence of ovulation points or corpora lutea.

Upon being paired, some of the thirty-two females fought until dominance was established, and subsequently only the dominant doe of each pair mounted and displayed copulatory pelvic thrusts. During the 2-week experimental period, ovulations occurred among seven of the original sixteen doe-pairs. In every case ovulation occurred in the submissive doe of the pair. One oestrous female $(2.5 \mathrm{~kg}$ body weight) was dominant to six successive oestrous partners. Her first partner $(1.8 \mathrm{~kg})$ became non-receptive on the 4th day; five further partners $(1 \cdot 8,2 \cdot 5,2 \cdot 4,2 \cdot 3$ and $3 \cdot 1 \mathrm{~kg})$ became non-receptive during the first 2 days of pairing. Autopsies confirmed that each of these submissive does had 
ovulated. The dominant female still had not ovulated when autopsied at the termination of the experimental period.

The doe-pairs that did not ovulate during the study consisted of those in which little mounting activity occurred and/or in which definite dominance and submissiveness was not established.

Three does that became non-receptive did not ovulate. It is assumed that they attained the natural termination of their oestrous state. Since the does were not checked for receptivity during the pre-experimental period, it was not known how long each doe had been receptive before the experimental period.

\section{Experiment 4: Pairing of oestrous with anoestrous does}

After being caged individually for at least 18 days, five females that were found to be receptive were laparotomized the succeeding day. Since none of these five females had ovulated, they were then paired with five additional does that were non-receptive. During the first day's activity (Day 1), it was ascertained that two that were receptive became dominant and that two further receptive ones were dominated by their non-oestrous partners. On Day 2 receptivity of all does was again checked with males. All of the does which were non-receptive the previous day were still non-receptive, but one of those previously receptive that was submissive on Day 1 was observed to be non-receptive. Laparotomy on Day 3 revealed the presence of recent ovulation points on the ovaries of the latter doe, but not on the ovaries of the four remaining receptive ones. On the 4th day following re-pairing, 6 days after the laparotomy, the remaining submissive oestrous doe became non-receptive; therefore, this female and the three does remaining in oestrus were again laparotomized. Only the submissive doe had ovulated; the remaining does still had large follicles present on their ovaries.

Hence, ovulation occurred among receptive females even though they were paired with non-receptive ones; however, when ovulation did occur, it was as a result of the receptive female being mounted and not by her being the aggressor.

\section{DISGUSSION}

A means commonly used for selection of oestrous from anoestrous does has been the appearance of the vulva (e.g. Sawyer et al., 1950; Hafez, 1964); however, this method has not been totally reliable (Hammond, 1925; Asdell, 1946; Carlyle \& Williams, 1961). Oestrous does have also been obtained by administration of hormones (e.g. Bishop, 1957) or selected by inspection of ovaries at laparotomy (Holmdahl \& Mastroianni, 1965). These techniques were presumably employed to minimize the chance of ovulation occurring when testing for oestrus by the lordosis response in the presence of a male (Hammond, 1925; Templeton, 1940).

In the current study, arching appeared to be a reliable test for selecting oestrous from anoestrous does in that ovulation was not induced after more than forty single, and two hundred multiple exposures of receptive females to 
males, during which each doe arched upon being mounted, provided the does were otherwise caged individually. These results are not in agreement with those of Hammond (1925) and Templeton (1940). Hammond (1925) reported that two of six oestrous females ovulated after they were mounted, but not penetrated, by a buck. Penetration was prevented by placing a hand between the mounted buck and the doe. Attempts to repeat these findings failed as the oestrous does used did not arch when subjected to the conditions as described. Ovulation did not occur in the current study if penetration was prevented by pushing aside the males' hindquarters when the females arched or among five additional females that were fitted with plastic diapers to prevent coitus even though each arched well during a 1-min cohabitation. These results also do not confirm those of Templeton (1940) in which one of three New Zealand does ovulated upon being mounted by a buck. Explanation of the difference is not possible since neither the means used for preventing vaginal penetration, nor the number of mating attempts were reported.

The caging of oestrous females next to males revealed that visual and olfactory factors, even when combined with daily archings, did not induce ovulations among twelve does over a 2-week period. If ovulation is possible at all following such proximity of an oestrous doe to a male, its occurrence is at least very rare.

Thus, in this study oestrous females that were mounted but not penetrated by bucks did not ovulate; but oestrous does paired with and mounted by other does did ovulate. The different response is believed to be related to the degree of excitement attained by the submissive female. Oestrous does were subjected to males usually only once a day, and never more than three times a day, but when does were paired the submissive doe was mounted exhaustively by her dominant partner. Ovulations were never noted unless this degree of stimulation was present.

Ovulation was reported to occur in the dominant female following the mounting of another female during which the dominant female made copulatory movements (Brooks, 1937-one case) and was observed even to fall off with a cry characteristic of that made by males during ejaculation. In the current study, dominant females were observed to exhibit pelvic thrusts, and the submissive female was observed to arch and to maintain this posture for up to $1 \mathrm{~min}$; but never was the dominant female observed either to fall off with a cry or to have ovulated following continued pairing for a period extending to 17 days. It was also noted that a doe that was dominant in one case could become submissive and then ovulate when placed in the company of another doe. The larger female was not always the dominant one.

Ovulation is believed to be due to some component of the orgasm which accompanies coitus rather than to the mechanical stimulus of the penis or the presence of semen in the vagina (Hammond, 1925; Walton \& Hammond, 1928). To determine whether the clasp of an ejaculating male would be sufficient stimulation to induce ovulation in oestrous does, such does were used as teasers for semen collection via an artificial vagina. The lack of ovulation, however, may have been due to the fact that to collect the semen some of the weight had to be taken off the does' hind legs. It was reported by Brooks 
(1937) that the doe must co-operate with her hind legs during coitus for ovulation to occur.

Young, gonadotrophin-primed does are known to ovulate without subsequently forming corpora lutea (Parkes, 1943) and that young does will mate before ovulation is possible (Hammond, 1925). To ensure sufficient maturity for LH-induced ovulation among Dutch-belted does of unknown age, body weight should be more than $1.75 \mathrm{~kg}$ (Staples \& Holtkamp, 1966). To be relatively certain that only mature does were used in the present study, only those weighing more than $1.75 \mathrm{~kg}$ were used. However, even mature oestrous does do not always ovulate following coitus. For example, of thirty-eight naturally bred, Dutch-belted does ( 1.90 to $2.80 \mathrm{~kg}$ body weight), isolated for at least 18 days before coitus, that served as untreated controls for studies run concurrently with that now presented, six had not ovulated when autopsied 5 to 6 days post coitum. Brooks (1937) stated that ovulation failures may be due to insufficient stimulation during the mating process.

Ovulation was not induced in this study by causing oestrous females to arch once daily when mounted by a male, whether retained in his presence or not. Also, ovulation was not induced in oestrous does which assumed the dominant role when paired with other females. It is not possible to state that ovulation will never be caused by these factors, for a positive statement cannot be made from negative data, but it is hoped that the information contained will be added to by the work of others in Dutch-belted and other breeds of rabbits to reveal ultimately those behavioural factors, short of coitus, most likely to induce 'spontaneous' ovulations among oestrous does.

\section{ACKNOWLEDGMENTS}

This investigation was supported by Public Health Service Research Grant Nos. CA 02193-11S1 and HD 01785. The author gratefully acknowledges the technical assistance of Helen D. Geils, Mary Jane Hepinstall and Judith Anika.

\section{REFERENCES}

Asdell, S. A. (1946) Patterns of mammalian reproduction, pp. 44 and 192. Comstock, Ithaca, New York.

Bishop, D. W. (1957) Metabolic conditions within the oviduct of the rabbit. Int. 7. Fert. 2, 11.

Brooks, C. McC. (1937) The role of the cerebral cortex and of various sense organs in the excitation and execution of mating activity in the rabbit. Am. 7. Physiol. 120, 544.

Carlyle, A. \& Williams, T. D. (1961) Artificially induced ovulation in the rabbit. 7. Physiol., Lond. $157,42 P$.

Fee, A. R. \& PARkes, A S. (1930) Studies on ovulation. III. Effect of vaginal anaesthesia on ovulation in the rabbit. 7. Physiol., Lond. 70, 385.

Foote, R. H., Hafs, H. D., Staples, R. E., Gregoire, A. T. \& Bratton, R. W. (1963) Ovulation rates and litter sizes in sexually receptive and non-receptive artificially inseminated rabbits given varying dosages of luteinizing hormone. 7. Reprod. Fert. 5, 59.

Garcia, C. R. \& Rock, J. (1958) Ovulation. Essentials of Human Reproduction, p. 29. Ed. J. T. Velardo. Oxford University Press, New York.

HAFEz, E. S. E. (1964) Seasonal fluctuations in ovulation rate and super-ovulatory response of the domestic rabbit (Oryctolagus cuniculus). Acta zool., Stockh. 45, 123.

Hammond, J. (1925) Reproduction in the rabbit, pp. 44 and 70 . Oliver \& Boyd, Edinburgh.

Hammond, J. (1930) The control of fertility in the rabbit. Wld's Poult. Congr. 4 (Sec. F), 957.

Hammond, J. \& Asdell, S. A. (1926) The vitality of the spermatozoa in the male and female reproductive tracts. Br. J. exp. Biol. 4, 155. 
Hammond, J. \& Marshall, F. H. A. (1914) The functional correlation between the ovaries, uterus, and mammary glands in the rabbit, with observations on the oestrous cycle. Proc. R. Soc. B, 87, 422.

Heape, W. (1905) Ovulation and degeneration of ova in the rabbit. Proc. R. Soc. B, 76, 260.

Hill, R. T., PARkes, A. S. \& White, W. E. (1934). The assay of the ovulation-producing substance. 7. Physiol., Lond. 81, 335.

HolmdahL, T. H. S. \& Mastroianni, L., JR. (1965) Gontinuous collection of rabbit oviduct secretions at low temperature. Fert. Steril. 16, 587.

Nalbandov, A. V. (1958) Reproductive physiology: comparative reproductive physiology of domestic animals, laboratory animals and man, p. 134. Freeman, San Francisco.

PaRkes, A. S. (1943) Induction of super-ovulation and super-fecundation in rabbits. F. Endocr. 3, 268.

Pincus, G. (1948) Discussion in Recent Progr. Hormone Res. 2, 129.

SAWYER, C. H. (1949) Reflex induction of ovulation in the estrogen-treated rabbit by artificial vaginal stimulation. Anat. Rec. 103, 502.

SAWYER, C. H. (1959) Seasonal variation in the incidence of spontaneous ovulation in rabbits following estrogen treatment. Endocrinology, 65, 523.

Sawyer, G. H., Everett, J. W. \& MARkeE, J. E. (1950) 'Spontaneous' ovulation in the rabbit following combined estrogen-progesterone treatment. Proc. Soc. exp. Biol. Med. 74, 185.

Shibata, S. (1931) The oestrous cycle and ovulation in the rabbit. F. Coll. Agric. imp. Univ. Tokyo, 11, 309.

StAPLES, R. E. \& HoltKamp, D. E. (1966) Influence of body weight upon corpus luteum formation and maintenance of pregnancy in the rabbit. F. Reprod. Fert. 12, 221.

Templeton, G. S. (1940) Pseudopregnancy in domestic rabbits. Wildl. Circ. 4, 1.

WALton, A. \& HAMMOND, J. (1928) Observations on ovulation in the rabbit. Br. F. exp. Biol. 6, 190.

YAMANE, J. \& EGASHIRA, T. (1925) On the relation of copulation to ovulation in the rabbit as shown by means of artificial insemination. F. Fap. Soc. vet. Sci. 4, 110. 